\title{
BARTON, D. \& HAMILTON, M. LOCAL LITERACIES: READING AND WRITING IN ONE COMMUNITY. LONDRES E NOVA YORK: ROUTLEDGE, 1998, 299 PÁGS.
}

\author{
Resenhado por: Edna Cristina S. Santos
}

O que as pessoas fazem com a linguagem escrita é uma parte de suas vidas e de como vivem. Ler e escrever são atividades humanas complexas e inseparáveis dos lugares e das relações sociais em que ocorrem. Por isso, o presente livro sugere um senso de lugar e de comunidade que nos conduz a refletir sobre onde estamos e como os letramentos locais caracterizam, organizam, compõem e transformam nossas vidas.

Local literacies: reading and writing in one community é um estudo que focaliza as atividades sociais e os significados que permeiam as práticas de letramento. Investiga como um grupo particular de pessoas usa a escrita e a leitura diariamente em sua comunidade e em seus lares, incluindo usos contemporâneos de letramento (como o computador) e como os significados de letramento estão mudando. Mostra que, por meio das atividades de letramento cotidianas e domésticas - como anotações de endereços e números de telefone, recebimento pelo correio de contas, faturas, impostos, propagandas de lojas e serviços - somos conectados às outras pessoas, além de sermos definidos como consumidores, devedores, pagadores de taxas, trabalhadores e cidadãos.

Barton e Hamilton concebem o letramento como prática social, por propiciar a relação entre atividades de leitura e escrita e as estruturas sociais nas quais se encaixam e ajudam a moldar. Apresentam um grupo de seis proposições sobre a natureza do letramento:

1. O letramento é melhor compreendido como um conjunto de práticas sociais, inferidas a partir de eventos que são mediados por textos escritos;

2. Há diferentes tipos de letramentos associados a diferentes domínios da vida; 
3. Práticas de letramento são modeladas pelas instituições sociais e relações de poder, e alguns letramentos tornam-se mais dominantes, visíveis e influentes do que outros;

4. Práticas de letramento são intencionais, premeditadas, encaixadas em objetivos sociais mais amplos e em práticas culturais;

5. O letramento é historicamente situado;

6. As práticas de letramento mudam, e novas práticas são freqüentemente adquiridas através de processos significativos de aprendizagem informal.

Os autores apresentam uma visão geral da história de letramento de Lancaster, onde foi realizada a pesquisa, para mostrar como o presente é feito do passado. Ressaltam a importância de fixar um período preciso para localizar as práticas de letramento no tempo. Os anos da década de noventa foram fixados como um momento histórico importante tanto no que se refere aos recursos tecnológicos disponíveis, como computadores pessoais, aparelhos de fax e telefones móveis, quanto em termos das questões sociais e políticas do dia-a-dia, tais como o imposto de votação e o desemprego. Nessa época, os jornais de Lancaster noticiam sobre os padrões de leitura nas escolas, a Guerra do Golfo, Margaret Thatcher e, principalmente, o imposto de votação. Um tempo e um lugar caminham juntos nesta pesquisa em 1990. A compreensão das práticas sociais dos encontros da associação de moradores ou da produção do boletim informativo local depende da compreensão da história do lugar e do momento atual no tempo, porque inclui, por exemplo, o conhecimento sobre qual tecnologia estava disponível e qual acesso a comunidade tinha aos recursos materiais, como processadores de textos, por exemplo.

Para desenvolver este estudo, os autores utilizaram o método da pesquisa etnográfica, qualitativa e colaborativa, porque permite o exame detalhado do papel do letramento na vida contemporânea das pessoas, em suas histórias e tradições. Foram realizadas entrevistas, observações, estudo de casos e história oral. Justificam a escolha desse método porque: (a) a etnografia estuda ambientes do mundo real; (b) visa a fenômenos completos; (c) o trabalho envolve múltiplos métodos e se vale de uma 
variedade de técnicas de pesquisa; (d) a etnografia é interpretativa e objetiva representar as perspectivas dos participantes. Preocupam-se em explicitar a metodologia adotada porque, além de permitir que a pesquisa seja avaliada por outras pessoas, têm consciência de que não estão utilizando uma metodologia pronta e aleatória, mas que foi modelada ao longo da pesquisa, em que novas estratégias puderam ser adaptadas e evoluídas. Tentam interpretar e explicar os dados coletados no sentido de tornálos inteligíveis em um quadro teórico de práticas culturais e sociais, o que permite a compreensão do letramento em outros contextos. Tais explicações são essenciais a qualquer estudo empírico porque, sem elas, os dados não podem ser interpretados, sejam eles quantitativos ou qualitativos. Segundo Street (1997), não é suficiente apenas descrever a riqueza e a variedade das práticas de letramento por meio de coletas etnográficas detalhadas. É necessário reconhecer o papel central das relações de poder nas práticas de letramento.

Uma teoria social de letramento assenta-se nos conceitos de práticas, eventos e textos, a fim de analisar o evento para compreender as práticas. Práticas de letramento são modos culturais de utilização da linguagem escrita por meio dos quais as pessoas traçam suas vidas. Envolvem valores, atitudes, sentimentos e relações sociais representados por meio de ideologias e identidades sociais. Conectam as pessoas entre si, regulando o uso e a distribuição de textos e prescrevendo quem pode produzir e ter acesso a eles. Eventos de letramento são atividades em que um texto escrito desempenha um papel central, constituindo-se em episódios observáveis que emergem das práticas e são modelados por elas. Um evento de letramento pode integrar a linguagem escrita e a falada como parte de uma série de sistemas semióticos que incluem números, notações musicais, mapas, gráficos, tabelas e outras imagens sem texto. Por exemplo, receitas culinárias misturam números e palavras e provêm de livros, revistas, televisão, computador e de amigos e parentes, via oral. Os textos podem desempenhar múltiplos papéis em um evento de letramento, dependendo do que as pessoas fazem com textos e que significados atribuem a essas práticas, visto que mediam relações sociais. Um enfoque social de letramento requer que as práticas sejam significativas e que as pessoas se conscientizem de que a compreensão que têm da leitura 
e da escrita afeta o seu uso e sua aprendizagem. Qualquer teoria de letramento implica uma teoria de aprendizagem, posto que as práticas de letramento mudam e novas práticas são adquiridas através de processos de aprendizagem informal que ocorrem em contextos sociais particulares. A compreensão que as pessoas têm de suas práticas de letramento é um aspecto importante de sua aprendizagem, porque guia suas ações.

Os estudos sobre letramento caracterizam-se por sua natureza interdisciplinar, porque articulam abordagens históricas e sociológicas de teóricos como Giddens (1991) e Foucault (1972; 1977) cujas perspectivas propiciam a compreensão de como localizar as práticas de letramento no interior de práticas sociais mais amplas e de como o senso de identidade social é formado pelas práticas e pelos processos de mudança social. Por sua vez, os estudos sobre letramento contribuem com pesquisas sobre discurso e processos sociais devido à ênfase sobre a análise das práticas e de textos, além de focalizar a importância dos textos escritos nas formações discursivas de instituições sociais poderosas. Uma outra perspectiva de estudos na área de letramento é fornecida pelos estudos da linguagem e do discurso orientados pela teoria social, tais como a elaboração da análise de discurso crítica de Norman Fairclough (1989), a teoria semióticosocial de Gunther Kress (Kress \& Hodge, 1988) e os trabalhos de James Gee (1990; 1992) e Jay Lemke (1995) sobre discurso e processos sociais.

Em artigo intitulado "The texts of everyday life: public and private identities in vernacular literacy practices", Hamilton e Barton (1999) ressaltam a contribuição de pesquisas sobre letramento para a metodologia da análise de discurso ao relacionar o estudo de letramento como prática sócio-cultural e o estudo detalhado de textos significativos em um processo de triangulação, que compreende observações das práticas de letramento, entrevistas sobre as práticas e análise dos documentos implicados nessas práticas. Mostram a importância do estudo de textos coletados em práticas e eventos de letramento cotidianas, textos da vida pessoal gerados no curso de atividades que são criadas pelas pessoas e que circulam localmente. Por não serem textos que se originam em instituições e discursos dominantes, como textos educacionais e provenientes da mídia, são mais fluidos, criativos e híbridos, do ponto de vista de suas características discursivas. São estudos dos quais emergem questões sobre identida- 
de e sobre como são negociadas no interior do texto. Por exemplo, na análise das práticas de letramento de determinada pessoa, é possível observar como ela se move de uma identidade privada para uma identidade pública, de políticas de vida pessoal para políticas da comunidade local, associando as tensões e as possibilidades nessas trocas de papéis.

A contribuição deste livro consiste em fornecer subsídios para estudos que investiguem as práticas de letramento em outros domínios tais como: instituições sociais formais (escolas, hospitais, igrejas, associações de moradores, sociedades comerciais, prisões, locais de trabalho, etc.); os letramentos vernaculares, que têm origem na vida diária e em contextos informais; a relação entre letramentos impressos e outras mídias. Também podem ser feitas pesquisas sobre o papel do letramento na construção de identidades de etnia, gênero, religião. Todos esses estudos permitem compreender como o letramento é posicionado nas práticas sociais e nas relações de poder que as sustentam. De acordo com Carvalho (2001:189-193), além de fornecer descrição detalhada das práticas de letramento de uma comunidade, Local literacies apresenta orientações para estudos etnográficos e contribui para melhorar a qualidade de vida de uma comunidade. É leitura recomendada a pesquisadores, professores e estudantes que se interessem pela natureza dos letramentos cotidianos, geralmente negligenciados nos discursos dominantes sobre os usos da escrita, e pelas discussões sobre letramento, educação e qualidade de vida que visem a transformação e a emancipação social.

\section{REFERÊNCIAS BIBLIOGRÁFICAS}

Barton, D., Hamilton, M. \& Ivanic, R. Situated literacies: reading and writing in context. Londres e Nova York: Routledge, 2000.

Carvalho, C. Cadernos de Linguagem e Sociedade. Brasília: Thesaurus, Vol. 5, 2001.

Fairclough, N. Language and power. Londres: Longman, 1989.

Foucault, M. The archeology of knowledge. Londres: Tavistock Publications, 1972. 
—. Discipline and punish: the birth of the prison. Londres: Allen Lane, 1977. Gee, J. Social linguistics and literacies: ideology in discourses. Londres: Falmer Press, 1990.

—. The social mind: language, ideology and social practice. Nova York: Bergin and Garvey, 1992.

Giddens, A. Modernity and self identity: self and society in the Late Modern Age. Cambridge: Polity Press, 1991.

Kress, G. \& Hodge, R. Social semiotics. Cambridge: Polity Press, 1988.

Lemke, J. Textual politics: discourse and social dynamics. Londres: Taylor and Francis, 1995.

Street, B. V. (org.). Cross-cultural approaches to literacy. Cambridge: Cambridge University Press, 1997. (Cambridge Studies in Oral and Literate Culture, 23) 